\title{
The Concept of Narration in the Place Brand Identity
}

\section{Lolita Ozolina}

Mg.sc.soc, Latvian Academy of Culture, Latvia

\begin{abstract}
The place branding as an integral part of competitive place development strategy became a topic for municipalities and cities of Latvia relatively recently, at the beginning of 2000. In particular, the issue of place identity exploration in Latvia has become a key subject, linked to the sustainable demonstration of the attractiveness of the place, narration of unique benefits in order to increase place's economic value and social welfare in behalf of place residents and other stakeholders. The author seeks answers to a range of interdisciplinary research questions related to the topic of place branding - how to create a place brand identity that is relevant to place residents and express the sense of place (identity); what are the main conditions of place brand development and what intangible and/or tangible attributes of identity provide convincing place brand identity narratives? The empirical part of the article is based on the methodology of qualitative research, in-depth semi-structured interviews with Latvian place branding experts, and analysis of the content of brand identities of Latvian cities and municipalities. The research insight was how place branding as a strategic marketing process is mastered by the local municipality and involved stakeholders, provides a critical view on the local practices, and strengthens the appreciation of the importance of place brand identity narratives.
\end{abstract}

Keywords: narrative, place branding, identity, sense of place, storytelling

\section{Introduction}

To succeed in a constantly changing world places must reinvent themselves to stay competitive and define mutually sustainable relationships with their people. According to Mihalis Kavaratzis one of the main resources of the place brand construction is narrative. In matter of fact, Kavaratzis suggests that place brands are better thought of as narratives or 'place stories' (Kavaratzis, 2015: 5). The concept 'narrative' is a set of valuable capital due to place- bound context and meaning formation of the respective place. For the place brand to become a narrative or to be designed as a narrative, the concept 'narrative' needs to be unraveled and explore in context of the terms of 'place' and 'identity'.

The concept 'narrative' has multiple relations between various disciplines including literary and culture studies, media studies, art history, sociology, and semiotics. Narrative as a term encounters not only academic texts but rotates in our everyday consciousness as habitual and regular ingredient. According to the thought of system theory narrative reflects the society's perception of itself at the operative level. Niklas Luhmann describes society as an active and lively system, which reproduces notions of oneself (self-reference) in communication, which also creates autopoiesis - self-renewal system. (Luhmann, 1996: xx) Thus, it not only 
contributes to the renewal of society, but also creates and reproduces identities as well as meanings and relationships.. ,"no system unity can exist between mechanical and conscious operations, between chemical operations and those that communicate meaning. " (Luhmann, 1996: 39) Because of the given self-reflecting and self-describing characteristics narrative becomes an important social source, professor Walter Fisher, the author of concept 'narrative paradigm' highlights the symbolic aspect of the narrative describing the concept as 'symbolic actions' - words and/ or deeds - that have sequence and meaning for those who live, create, or interpret them. (Fisher, 1987: 58) The symbolic actions a an asset is also recognized by the place branding expert Simon Ahholt noting that symbolic actions are emblematic for the place brand identity in the same time a component of the place story (Anholt, 2010: 13). Narrative has an intrinsic communicative power due to its historical and theoretical framework. According to Anne Pellowski, the author of several books on theory and practice of storytelling, describes storytelling (narration) as an entire context of the moment was an early entertainment, indicated more than 5,000 years ago (Pellowski, 1990: 3). The earliest origins of storytelling suggest that there is an evidence of several theories, including selfentertainment. The other theories: the need to explain the surrounding physical world, the need to communicate experience to other humans, to encode and preserve the norms of social interactions that a given society lived by, as well as an ideological and religious component of believes to the present world. (Pellowski, 1990: 10). Simon Anholt emphasizes the extensivity of symbolic actions in context of policies as "suggestive, remarkable, memorable, picturesque, newsworthy, poetic, topical, poetic, touching, surprising or dramatic" (Anholt, 2010: 13). According to Kavaratzis there is a close interrelation between symbolic representation and physical place-making and increasingly high need to consider the customers therefore, residents the co-creators of both representation and place (Kavaratzis, 2015: 161). Similarly, to Jerome Bruner this co-creation is "the most natural and the earliest way in which we organize our experience and our knowledge' (Bakhurst and Shanker, 2001: 27). Bruner emphasizes the importance of language but also highlights other symbolic artefacts and institutional influences in construction of narratives. Conceptually Bruner comprises that the culture is "the symbolic systems that individuals [use] in constructing meaning" (Bakhurst and Shanker, 2001: 27). Therefore, "we represent our lives (to ourselves as well as to others) in the form of narrative " (Bakhurst and Shanker, 2001: 23). Narrative becomes an identity content and at the same time a storage of countless identities of our cultural origins. Concerning more practical understanding of the concept of narrative in context of place brand identity, it is a research methodology of the tangible and intangible attributes of the place identity. Two sides tangibility and intangibility of the place identity is a common set of characteristics of place identity. Therefore, the process of narrating a story is useful in research for the content of place identity and co-creating the social reality comprehending both existing and inherited signifiers of the communal sense of place.

The diversity of genres and forms of narrative is another conceptual aspect in the context of place brand identity. Narrative is present in various forms of pictorial and verbal forms: myth, legend, story, tradition, history, news, conversation and so on, as well as, in every place, age, time and society. Regarding the narrative as a place there must be an extent value and rhetorical impact in order to find or design a credible narrative. One of terms that provides a credibility to narratives is a 'masterplot' or 'master narrative' (Abbot, 2008: 47) 'Master narrative' is understood "as a skeletal and adaptable " (Abbot, 2008: 47) powerful cultural force of the stories. The one the foremost thinkers in current folkloristic scholarship, Simon Bronner emphasizes the contribution of folklorists in cultural diversity and variations of 
narratives generated by ordinary people in different cultural groups who chose not to follow national or even universalized "master narratives" (Bronner, 2011: 20). The narrative at its essential mode is a verbal presentation process of telling stories and events or actions. Professor H. Porter Abbot describing narrative emphasizes the difference between terms 'event' and 'story' -"the difference between events and their representation is difference between story (the event or sequence of events) and narrative discourse (how the story is conveyed) " (Abbot, 2008: 15). Narrative discourse is characterized as true or false, historical, or fictional. Thus, the concept of an authentic narrative is often referred to as a credible aspect of place brand identity to maintain deeper mental and social relationships with an origins of place identity. Quite often places lose their origins and credibility of the meaning captured in a narrative within a time. Therefore, regarding to places as social constructions in marketing terms, the credible narrative becomes vital element that holds symbolic meanings created by people of the place, shared experiences, mediated in variety of controlled and uncontrolled communication channels. One of the most natural yet credible communication way is wordof- mouth. Narratives can become updated versions of the common memories, rituals, traditions, and stories, and other interpretations of culture that have sustained value of sense of place. The concept of narration has a potential of continuity through cultural heritage and reinforced values in different degrees of tangibility as physical settings and intangibility emotional bonds created through social experiences and interactions.

\section{The concept of identity within sense of place and place branding}

With a reference to the aim of this article to explore the specifics of the concept of narrative within a place brand identity, it is important to understand the concept 'identity'. The term 'identity' is a multidimensional and interdisciplinary construct infecting diverse articulations in the humanities and social sciences. The vast literature on nationalism un national identity, examines the concept as complex of varied means by which nations become aware of themselves (Aronczyk 2013: 15). Other words in context of place brand identity it is a construct of "who we are". Anthony D. Smith, historical sociologist of the interdisciplinary field of nationalism studies, defines five fundamental features of national identity: an historical territory (homeland); common myths and historical memories; a common, mass public culture; common legal rights and duties for all members and a common economy with territorial mobility for members (Smith 1991: 14). Smith admits that the nation provides a social bond between individuals and classes by providing repertoires of shared values, symbols, and traditions (Smith 1991: 16). Smith emphasizes that identity is perceived as a thought of 'belonging to culture', it can be rational and based only on a sense of belonging to a common history and experience in which language takes an important role. From folklore studies point of view, Simon Bronner notes the concept 'traditions' [refence to common knowledge that has a symbolic gesture produced in actions] and term 'folk' that describes modifier signals, expressive forms such as stories, games, rituals, houses, and crafts that are learned and transmitted in the unofficial social settings of family, play, work, and community (Bronner 2011: 20). Therefore, Bronner's understanding of the tradition appear to be collectively understood and similar to Smith, involving common heritage, continuity in time, implied social connections and recreation. Tradition may occur as something new and old at the same time and something new within the old forms. The term 'traditional' in the context of shared values connotes stability, ordinality and security. Exploring various social and cultural influences of the identity construction the notion of 'human nature' must be considered. Not only in means "of the belonging to a tradition, to a particular discursive space, 
with its own order, reality, and truth, is necessary condition for the sort of experience" (Freeman, 1997: 212) but also a deep ties to the place. The author of the book "Place and Placelessness" Edward Relph (1976) cites author Simone Weil: "to be rooted is perhaps the most important and least recognized need of the human soul. It is one of the hardest to define. A human being has roots by virtue of his real, active and natural participation in the life of the community" (Relph, 1976: 39) Thus, referring to A. D. Smith's notion 'homeland', the notion 'home' is often exploited as a synonym of the nation and also describing the identity of the place. Metaphorically 'home' as a self-describing construct integrates both, tangible and intangible attributes and is used as a concept in brand identities of several Latvian cities and municipalities. In traditional means 'home' identifies a meaning that is proven through times, welcomed and secure place of the family and ancestors. Besides Relph describes 'home' as an authentically significant and inseparable asset (Relph, 1976: 39). This deeply internal aspect provides an experience to cultivate individual identity and at some extant can be mediated externally. In general people tend to define an individual's identity in the context of a network of affiliation as part of larger system such as family, group of friends, associates, or fellow residents (Pogorzelski, 2018: 172). According to Peter Davis and his work "Eco museums. A sense of place" refers on theories of Edward Relph describing various levels of place identity starting from my place, street, community, town, county, region, country, and continent (Davis, 2011: 22). Respecting these overlapping interpretations, the place identity culturally is defined as a "combination of the features and other elements or experiences. To that we must add the meaning of these tangible and intangible components - why are they important to that place? - and understand the relationship of these factors'" (Davis, 2011: 23). Similar view expresses Kavaratzis: "Place identity is a concept used in other disciplines including environmental psychology and geography" (Kavaratzis, 2015: 66). Furthermore, Kavaratzis notes that place identities are inherently fluid, and they tend to change (Kavaratzis, 2015: 67). One of the most common characteristics of the brand identity is based on difference. Therefore, the concept of uniqueness relies on the sense of place. To understand the meaning of the uniqueness there is one constant process - meaning-making processes between people and their place. Such terms as 'belonging to place' and 'sense of place' are used as synonyms of place identity. The term 'place' is a desirable object of research in various disciplines such as cultural and heritage studies, anthropology, ecology and geography, psychology, and sociology. Place and people are entwined with theories and interpretation of identity. Peter Davis cites Meinig (1979) "that (Western) people see landscape as nature; as habitat; as an artefact; as a system; as a problem; as wealth; as ideology; as history; as place or as aesthetic " (Davis, 2011: 20). Another acknowledgement of the place is being in the place or experiencing it. According to Laurajane Smith experiences of the particular place plays a significant role in understanding the meaning of place heritage. "Heritage as place, or heritage places, may not only be conceived as representational of past human experiences but also of creating an affect on current experiences and perceptions of the world. Thus, a heritage place may represent or stand in for a sense of identity and belonging for particular individuals or groups " (Smith, 2006: 77). Socially engaging experiences, a kind of narrated knowledge is intangible culture heritage - "the practices, representations, expressions, knowledge, skills - as well as the instruments, objects, artefacts and cultural spaces associated therewith - that communities, groups and, in some cases, individuals recognize as part of their cultural heritage" (UNESCO Convention, 2003). Culture heritage provides an essential source of shared identity interpretations and experiences of the place. There is a social link between people and place, and between people and people. The term 'sense of place' holds the characteristics of social interactions and 
reproductions of a community, and stands for the characteristics of the social capital, symbolic capital, and habitus of a place (Bourdieu, 1977). However, exploring the theories of the sense of place there are several issues how to identify and evaluate various dimensions of the place. For example, how to evaluate and compare quantitatively the "aesthetic quality of different landscapes," and to "quantify scenic beauty" (Carlson, 1999: 30); the Relph's reference to 'authenticity' "still connotates that which is genuine, unadulterated, without hypocrisy, and honest to itself" (Relph 1976: 64) is challenging not to get caught in stereotyped conventions. Therefore, it is more challenging to research and emphasize the emotional, cognitive, and aesthetic intangible attributes of sense of place in order to create the master narrative. Less demanding is the complex of tangible attributes of the place that include such place elements as historical buildings, artefacts, landscapes with intangible features such as traditions. These mutual interactions express tangible context of local habitat and surrounding values.

Referring to a place marketing approach introduced by Philip Kotler in early 90 ties in the 20th century, the brand identity was defined as a meaning designing of place to satisfy the needs of the target markets (Kotler 1993: 99). The concept of brand identity has come to the fore in recent years with an increase in academic work as well as practitioner growing interest. According to Melissa Aronczyk academic discourse of nation identity studies has slightly changed to political and social project of special representation and as a producer of value and values - has been altered by its conception as a brand (Aronczyk 2013: 14). Similar though expresses Simon Anholt, referring to places (countries) that "they need to exercise some power of attraction... unique, individual identity, their culture, their history, their land, their traditions, their genius and their imagination. This is what competitive identity is all about" (Anholt, 2010: 37) and this approach is more challenging because it is understood as policy- based. Place branding expert Keith Dinnie defines place brand identity as shared assets of the place, its personality, and desirable attributes. Mechanisms and environment must be conducive to encourage community participation and support of the brand strategy (Dinnie 2011: 13) and as "an affective bond or link between people and specific places"" (Kavaratzis 2015: 42). Many aspects of sense to place as an asset of the place brand identity is still underexplored in academic literature: how to define unique symbolic meanings and discourses that surround the place, its people and can be used as a core of the symbolic and ideological representation of place identity? Keith Dinnie emphasizes the notion of shared identity as a crucial to creating a place brand - a summary that captures the truthful story and uniqueness of the place (Dinnie 2011: 57).

\section{Empirical study}

To explore the main issues of creation place brand identities of Latvian cities and municipalities the four in-depth interviews were conducted with Latvian place branding experts of various fields: brand communication strategies, visual identities, and brand concepts. The empirical study also includes the content analyses of 27 Latvian place brand identities, specifically slogans and identity stories. The issue of identity creation and maintenance of Latvian cities and municipalities is relevant on the eve of the Administrative Territorial Reform, which is due in the mid-2021. This reform will include the transformation of 119 counties into 42 municipalities.

Regarding the multifaced characteristics of the sense of place and its unique assets it was proposed in theoretical framework that the research of place identity attributes within intangible cultural heritage. The traditional culture values and symbols of the place identity 
provide an orientation in heritage values as well as reflect the basic diverse characteristics. The assumption of the heredity of past meanings and its continuity in present environment is quite crucial. In means of creation place brand identity it refers to designing an up-to-date narrative. Place branding experts admitted that they do not see strict boundaries between tangible and intangible cultural heritage when it comes to research for the unique attributes of place identity. It goes without saying that values of cultural heritage that are recognized internally and externally are more acceptable and credible. This acceptance very much correlates with the place residents' perception with the place image at the wider level national identity:

City Kuldiga has UNESCO heritage river Rumba and capitalize on culture heritage in their identity. Then at the next level of place identity symbols, we lookfor images, elements that describe the national identity.

Continuing about unique attributes of the place identity the branding experts referred to the strong prioritization of tangible place-specific attributes: landscapes, architectural and/ or historical buildings, even animals and birds. This inference quite often is reinforced with the lack of competitive and sustainable place brand vision and strategic development:

In most cases, defined attributes of place identity are situational. Local governments are divided into dreamers and in those who have large budgets. The most of them act situationally and functionally. Most often they are shocked by the question, what are your strategic goals? As far as Valmiera and Cesis are ambitious on foot, they are strategically sharp. The others, like Gulbene, only a small part of residents who want to change things, but the vast majority seniors want stability, nostalgia of swans (symbols in Gulbene city coat of arms), only small part ofplaces try to understand who they are?

Besides geographical place attributes a common concept that appear in Latvian place brand identities is definition of 'home'. The notion of homeland, family, roots of the kin is the emotional reference with a component of pride when argued about belonging to place:

To the question of what you are proud of: the vast majority answer - it is cool to live here, but I cannot tell you why? The say it is my home, here is my family. If you externally can provide the place attributes to be proud of why you live here, then he will think. Geographical and cultural heritage matters, there are places with history, beautiful nature, and destinations, and then there are sad places that need help, who have a hard time finding narratives, finding perspectives.

The complexity of various stakeholders of the place, characterized by different levels of relationships and interpretation of the place identity occurs as a form of multiple and fluid meanings. These socially constructed interpretations of the place identity can be influenced by the trustful communication sources and credibility of the narrative of place identity. It is a matter of a strong indications of the shared identity elements that place residents have agreed on and accepted:

The most common problem often occurs within the residents are tired of place stories because they hear it every year, because it seems for eternity. Due to their ethnographic behavior or their slightly low self-esteem, they need repeatedly demonstrate that what they experience is exceptionally good. 
Previous assumption also illustrates the importance of process of place branding. It is first and foremost an internal co-creational and educational process of all involved parties of the creation of place brand. More important, it is not only a co-creation the stage of place brand identity creation but also in place brand revitalization and maintenance. Therefore, the formation of unique master narrative is crucial in means of the policy-based capacity of the place and recognition competitive and spacious narratives:

The fact that 119 municipalities are pulling up their brands is a horror. It is difficult to imagine 119 unique place brands. Most of them are large parts of artificial structures, such as Staicele "City of storks." It is necessary to think of and to know seven moves forward. Therefore, Sigulda's concept of "excitement" allows a wider range of identity narrative and its interpretation.

The interviews with the branding experts reflect the transmission from the specific place marketing projects to strategic place brands and also demonstrates an appearance of broader and ambiguous concepts of place brand identities. This assumption demonstrates a progressive understanding of the place brand as a live construct and strategic marketing tool:

Transferring place identity stories to brand identity is a big challenge, the question is about the local capacity in brand implementation. The brand stories of Rezekne and Talsi have potential, stronger ideas of power to change. There is a growing awareness in the minds of local government and service providers as we put more emphasis not on the making and more on implementation of the brand. Otherwise place brands remain at a decorative level.

As mentioned before the place identity interactions that occur within physical settings have different degrees of tangibility and could be represented through narratives as a communication form. Place could be regarded as a social construction. Indeed, both conceptual directions of place brand identity assets together create the sense of place. It indicates the positive transition towards to the awareness of concept 'master narrative':

Narrative as the brand's identity form works for all audiences. Often, narrative is more important than visual identity. Local government tells stories. Creating a narrative is an enormous amount of work that we pay undeservedly little attention to. One is to write a heartbreaking story about who you are and develop a story, and the other is to continuity of the work with current and external audiences about the messages - who we are?

Narrative is viable when it is consistently co-created and experienced. Branding experts emphasize the role of professionalism and the ability to offer strategically bold and credible place identity narratives, as well as the place government's confidence and capacity to provide these narratives consistently and maintain a high level of engagement:

The shyness of brand implementers appears in applications of place narratives, because it is often easier to create a beautiful logotype. The job of branding experts is to teach to nurture the narrative, with self-confidence, to develop further, to reflect this narrative and to stop being shy. We do not know how to conduct a critical dialogue, as soon as there is opposition or criticism, doubts appear, this is the moment when narrative is important. Narrative significance is high, but it is low in existing place brand identities.

This article investigates the key components of a place branding focusing on the concept of narrative and place brand identity. The specific conceptual attributes that combine to construct a place's brand identity, origin, values, personality, residential composition, and 
shared identity assets overlap and reflect in the image of the place. Unfortunately, the master narrative of the place brand identity in majority of cases of Latvian place brands represent visual decorativeness and lack of sustainable narration. The term 'decorativeness' is understood as an expression of a brand identity in a form of technical guidelines and metaphorical description. The challenging issue is the identification of the unique place identity attributes and to engage place's people in the process of co-creating their place's brand in order to develop an identity that is credible, competitive and sustainable in the minds of all stakeholders it serves. Therefore, the concept of narrative requires a further empirical exploration of the relationships and experiences of the place and its people.

\section{References}

[1] Abbott, H. P. (2008) The Cambridge Introduction to Narrative. $2^{\text {nd }}$ Edition. Cambridge: University Printing House.

[2] Anholt, S. (2010). Places. Identity, Image and Reputation. New York: The Palgrave Macmillan.

[3] Aronczyk, M. (2013) Branding the Nation. The Global Business of National Identity. New York: Oxford University Press.

[4] Bakhurst, D., Shanker, S.G. (2011) Jerome Bruner Language, Culture, Self. London: Sage Publications.

[5] Bhabha, H.K. (1990) Nation and Narration. London: Routledge.

[6] Bronner, S. J. (2011). Explaining Traditions. Folk Behavior in Modern Culture. Lexington: University Press of Kentucky.

[7] Campelo, A., Aitken, R., Thyne, M., Gnoth, J. (2013) Sense of Place: The Importance for Destination Branding. Sage Publications. Vol. 53 (2). p. 154-166. Available: https://iournals.sagepub.com/doi/pdf/10.1177/0047287513496474?casa token=XW6Zc bwrl6UAAAAA:pu387-v45rWTC1UbGHkH uaAhOc--vc3- 5FsUp3q 960E08PFn4SVB TelBgp8EGybX3L7Yc7MH (viewed 31.07.2020)

[8] Carlson, A. (2000) Aesthetics and the Environment. The Appreciation of Nature, Art and Architecture. London: Routledge.

[9] Christou, A. (2006) Narratives of Place, Culture and Identity. Second-Generation Greek- AmericansReturn 'Home'. Amsterdam: IMISCOE Dissertations. Amsterdam University Press.

[10] Daves, P. (2011) Ecomuseums. A Sense of Place. $2^{\text {nd }}$ edition. New York: Continiuum

[11] Dinnie, K. (2011) City Branding. Theory and Cases. New York: The Palgrave Macmillan.

[12] Fisher W.R. (1987) Human Communication as Narration: Toward a Philosophy of Reason, Value, and Action. Columbia, South Carolina: University of South Carolina Press.

[13] Freeman, M. (1993) Rewriting the Self. History, Memory, Narrative. London: Routledge.

[14] Kavaratzis, M., Warnaby, G., Ashworth, G. (2015) Rethinking Place Branding. Comprehensive Brand Development for Cities and Regions. New York: Springer.

[15] Kotler, F., Haider, D. H., Rein, I. (1993) Marketing places. Attracting Investment, Industry, and Tourism to Cities, States, and Nations. New York: The Free Press.

[16] Luhmann, N. (1995) Social Systems. Stanford, California: Stanford University Press.

[17] Pellowski, A. (1990) The World of Storytelling. Expanded and Revised Edition. Brox: The H.W. Wilson Company. 
[18] Pogorzelski, J. (2018) Managing Brands in 4D. Understanding Perceptual, Emotional, Social and Cultural Branding. Bingley: Emerald Publishing House

[19] Relph, E. (1976) Place andPlacelessness. London: Poin Limited.

[20] Richardson, J. (1986) Handbook of Theory and Research for the Sociology of Education. In: Bourdieu, P. The Forms of Capital. Westport; CT: Greenwood, p. 241-58. Available:

http://www.socialcapitalgatewav.org/sites/socialcapitalgatewav.org/files/data/pa per/201 6/10/18/rbasicsbourdieu1986-theformsofcapital.pdf (viewed 31.07.2020)

[21] Smith, A. D. (1991) National Identity. London: Penguin books.

[22] Smith, L. (2006) Uses of Heritage. London: Routledge.

[23] Latvan president to promulgate Administrative Territorial Reform Law, LETA. Availabel:

[24] https://bnn-news.com/latvian-president-to-promulgate-administrative-territorialreform-law-

[25] 214590 (viewed 02.08.2020)

[26] UNESCO website. Available: https://ich.unesco.org/en/convention (viewed 02.08.2020) 